\title{
Serratacosa, a new genus of Lycosidae (Araneae) from the southern slopes of the Eastern Himalayas
}

\author{
Lu-Yu WANG ${ }^{1}$, Xian-Jin PENG ${ }^{2}$ \& Zhi-Sheng ZHANG ${ }^{3, *}$ \\ ${ }^{1,3}$ Key Laboratory of Eco-environments in Three Gorges Reservoir Region (Ministry of Education), \\ School of Life Sciences, Southwest University, Chongqing 400715, China. \\ ${ }^{2}$ College of Life Sciences, Hunan Normal University, Changsha 410081, Hunan, China.
}

*Corresponding author: zhangzs327@qq.com

${ }^{1}$ Email: wangluyu1989@163.com

2Email: xjpeng@126.com

$1 \odot$ https://orcid.org/0000-0002-5250-3473

$2 \odot$ https://orcid.org/0000-0002-2614-3910

3 ๑ https://orcid.org/0000-0002-9304-1789

${ }^{1}$ urn:1sid:zoobank.org:author:6C219212-8F77-4037-949C-1F17B252BFCE

${ }^{2}$ urn:1sid:zoobank.org:author:5CF67046-FAB4-43F1-AA72-ED2EB9741CD9

${ }^{3}$ urn:lsid:zoobank.org:author:4BDFD343-89C8-4F2A-89CF-2693EA443189

\begin{abstract}
A new wolf spider genus, Serratacosa gen. nov., is erected based on the type and new species, S. medogensis gen. et sp. nov. and two newly combined species, S. himalayensis (Gravely, 1924) (from Hogna Simon, 1885) and S. multidontata (Qu, Peng \& Yin, 2010) (from Pardosa C.L. Koch, 1847). All of them are from the southern slopes of the Eastern Himalayas. Descriptions of the new genera and species, and a redescription of $S$. multidontata are provided together with digital images, illustrations and a distribution map.
\end{abstract}

Key words. Wolf spider, new combination, new species, Tibet, taxonomy.

WangL.-Y.,PengX.-J.\&ZhangZ.-S.2021. Serratacosa, anew genus of Lycosidae(Araneae) from the southern slopes of the Eastern Himalayas. European Journal of Taxonomy 762: 96-107. https://doi.org/10.5852/ejt.2021.762.1455

\section{Introduction}

The southern slopes of the Eastern Himalayas are one of the most important biodiversity hotspots worldwide (Myers et al. 2000), having high species richness and a high number of endemic species, such as the spider genera Himalmartensus Wang \& Zhu, 2008 (Amaurobiidae Thorell, 1870) and Himalcoelotes Wang, 2002 (Agelenidae C.L. Koch, 1837), which are only known from this region.

The wolf spider family Lycosidae Sundevall, 1833 is the sixth most diverse spider group, comprised of 125 genera and 2430 valid species worldwide (World Spider Catalog 2021). Some well-revised genera have distinctive distributional regions, such as Acantholycosa Dahl, 1908 (revised by Marusik et al 
2004) found in Europe, Asia and North America; Hippasa Simon, 1885 (revised by Wang et al. 2015) found in Asia and Africa, Ovia Sankaran, Malamel \& Sebastian, 2017 (revised by Sankaran, Malamel \& Sebastian 2017 and Lu et al. 2018) found in China, Laos, Singapore and India. But many genera are still non-monophyletic and need to be further revised, such as Arctosa C. L. Koch, 1847 and Pardosa C. L. Koch, 1847 (Piacentini \& Ramirez 2019).

Two lycosid species, Hogna himalayensis (Gravely, 1924) and Pardosa multidontata Qu, Peng \& Yin, 2010, found on the southern slopes of the Eastern Himalayas, share similar characteristics, such as the strong, twisted, distal-end grooved terminal apophysis (sickle-shaped in the type species of Hogna, H. radiata (Latreille, 1817)) (Logunov 2020: 352, figs 19-23); simple and non-grooved in the type species of Pardosa, P. alacris (C. L. Koch, 1833) (Almquist 2005: 215, figs 214a-f), and the serrated median apophysis (unserrated in $H$. radiata and $P$. alacris) and inverted T-shaped epigynal septum (same as in $H$. radiata and $P$. alacris).

Here a new genus, Serratacosa gen. nov., is erected to accommodate these two species, $S$. himalayensis (Gravely, 1924) comb. nov. and S. multidontata (Qu, Peng \& Yin, 2010) comb. nov., along with the type species of the new genus, $S$. medogensis gen. et sp. nov. from the same area of China (Medog of Tibet).

\section{Material and methods}

All specimens are preserved in $75 \%$ ethanol and were examined, illustrated, photographed and measured using a Leica M205A stereo microscope equipped with a drawing tube, a Leica DFC450 camera and LAS software ver. 4.6. Male pedipalps and epigynes were examined and illustrated after dissection. Female genitalia were cleared in $90 \%$ lactic acid. Eye sizes were measured as the maximum dorsal diameter. Leg measurements are shown as total length (femur, patella and tibia, metatarsus, tarsus). All measurements are given in millimeters.

Morphological terminology follows Framenau (2007).

\section{Institutional abbreviations}

SWUC $=$ School of Life Sciences, Southwest University, Chongqing, China

$\mathrm{HNU}=$ College of Life Science, Hunan Normal University, Changsha, China

\section{Abbreviations for morphological terms used in the text and figures}

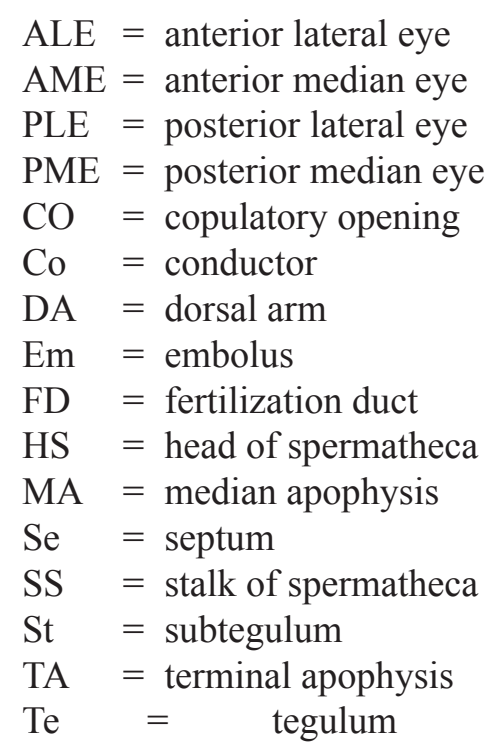


VA $\quad=\quad$ ventral arm

\section{Results}

Class Arachnida Cuvier, 1812

Order Araneae Clerck, 1757

Family Lycosidae Sundevall, 1833

Subfamily Lycosinae Sundevall, 1833

Serratacosa gen. nov.

urn:1sid:zoobank.org:act:DE9ED7B2-DB01-4C4B-8C29-6DE34846FFF7

\section{Type species}

Serratacosa medogensis gen. et sp. nov.

\section{Diagnosis}

This new genus shares similar characters with some Lycosinae genera, such as Costacosa Framenau \& Leung, 2013 (male pedipalps with serrated median apophysis), Hogna Simon, 1885 and Trochosa C. L. Koch, 1847 (epigynes with inverted T-shaped septum). However, the new genus can be distinguished from all above mentioned genera by: median apophysis ventral surface with a semicircular protruding lobe, strongly sclerotized, dorsal surface with an oval sclerite (with keel-shaped ventral spur in Costacosa, whereas in Hogna and Trochosa oblique, with stout spur near base); terminal apophysis twisted, strongly grooved (sickle-shaped in Costacosa, Hogna and Trochosa); embolus long, sinuous (arc-shaped in Costacosa, Hogna and Trochosa) (Figs 1, 2A-B, 3C-F, 4A-B, 5C-F). Epigynal septum as long as wide (Figs 2C-D, 3G-H, 4C-D, 5G-H) (longer than wide in Costacosa, Hogna and Trochosa) (Almquist 2005; Framenau \& Leung 2013; Logunov 2020).

\section{Etymology}

The generic name is derived from the Latin word 'serratus' ('锯齿状的' in Chinese), which means serrated, and the lycosid generic suffix '-cosa'; referring to the serrated anterior edge of the median apophysis; gender feminine.

\section{Description}

Cephalothorax. Carapace gray brown, with light brown longitudinal marking on mid-line, eye region black. Fovea longitudinal. Radial furrows distinct. Chelicerae brown, with three promarginal and three retromarginal teeth. Labium and endites yellow brown, longer than wide. Sternum yellow brown and scutellate, with sparse brown setae.

Legs. Yellow-brown, with black pigmentation. Leg formula: 4123.

Opisthosoma. Oval, yellowish-brown, with lanceolate cardiac mark on anterior half and with black irregular markings on posterior half. Venter of abdomen yellow-brown.

Pedipalps (Figs 1A, 2A-B, 3C-F, 4A-B, 5C-F). With slender and hooked embolus. Terminal apophysis twisted, strongly grooved. Median apophysis complex, serrated, with two arms: ventral arm earlobeshaped and dorsal arm oval, with apical end. Conductor small, membranous.

Epigyne (Figs 2C-D, 3G-H, 4C-D, 5G-H). With wide, inverted T-like septum, spermathecal heads nearly spherical, with stalks short and curved. Fertilization ducts hook-like. 


\section{Composition}

Three species: Serratacosa medogensis gen. et sp. nov., S. himalayensis (Gravely, 1924) comb. nov. and S. multidontata (Qu, Peng \& Yin, 2010) comb. nov.

\section{Distribution}

China (Yunnan, Tibet), India (West Bengal, Assam) and Bhutan.

\section{Remarks}

The types of Hogna himalayensis were unavailable for our research, but it is clear from the descriptions and figures of Tikader \& Malhotra (1980: 382, figs 255-257) and Buchar (1997: 14, figs 15-17), that the median apophysis is serrated and the epigynal septum inverted T-shaped.

Serratacosa medogensis gen. et sp. nov. urn:1sid:zoobank.org:act:734E2179-3E8D-4E2A-9AB7-D3947CC7F01B

Figs $1-3,6$

\section{Diagnosis}

This new species most closely resembles $S$. multidontata (Qu, Peng \& Yin, 2010) (Figs 4-5), but differs from the latter by the following characters. Lateral projection of the median apophysis with a blunt end,
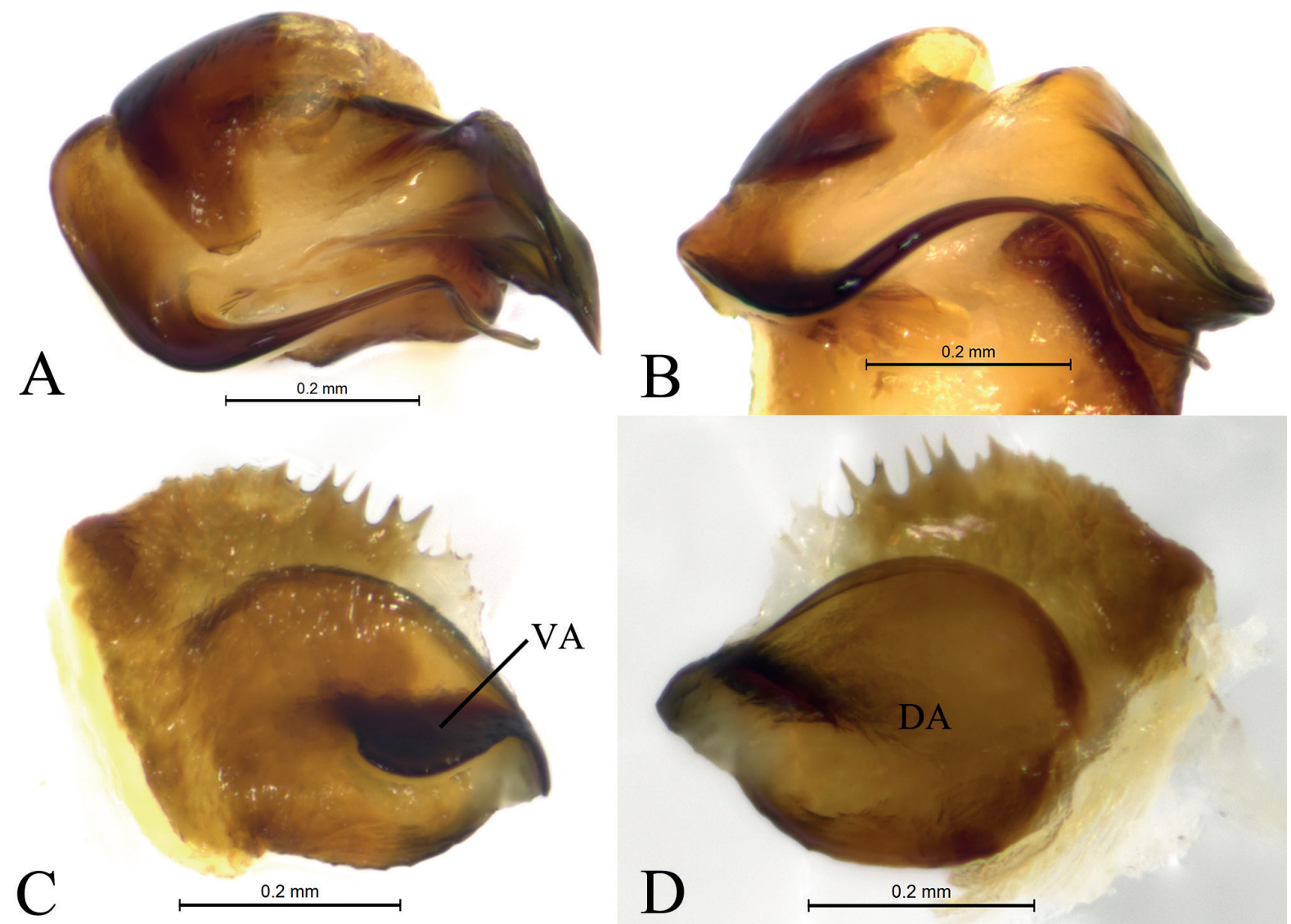

Fig. 1. Serratacosa medogensis gen. et sp. nov. A. Embolus and terminal apophysis, ventral view. B. Embolus and terminal apophysis, bottom view. C. Median apophysis, ventral view. D. Median apophysis, dorsal view. 
slightly touching lateral edge of cymbium in the new species (Figs 1C-D, 2A-B, 3C-F), whereas distal end truncate, almost overlapping lateral edge of cymbium in ventral view in S. multidontata (Figs 4AB, 5C-F). Septum wider than long and spermathecal heads spherical with fine spermathecal stalks in the new species (Figs 2C-D, 3G-H), whereas septum longer than wide and spermathecal heads oval with thick spermathecal stalks in S. multidontata (Figs 4C-D, 5G-H).

\section{Etymology}

The specific epithet refers to the type locality 'Medog' ('墨脱' in Chinese); noun in apposition.

\section{Type material}

Holotype

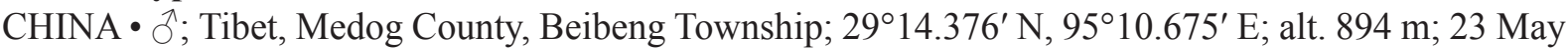
2019; L.Y. Wang, P. Liu, T. Yuan and H. Wang leg.; SWUC-T-LY-12-01.

\section{Paratypes}

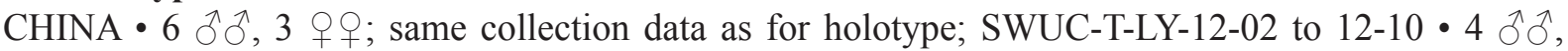

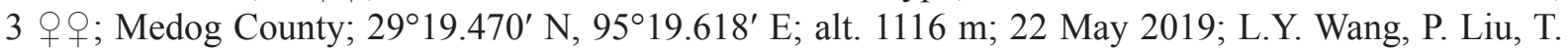

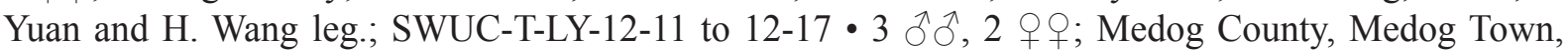
Yarang Village; $29^{\circ} 17.758^{\prime}$ N, $95^{\circ} 16.827^{\prime}$ E; alt. 761 m; 22 May 2019; L. Y. Wang, P. Liu, T. Yuan and H.

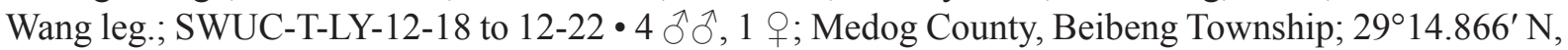

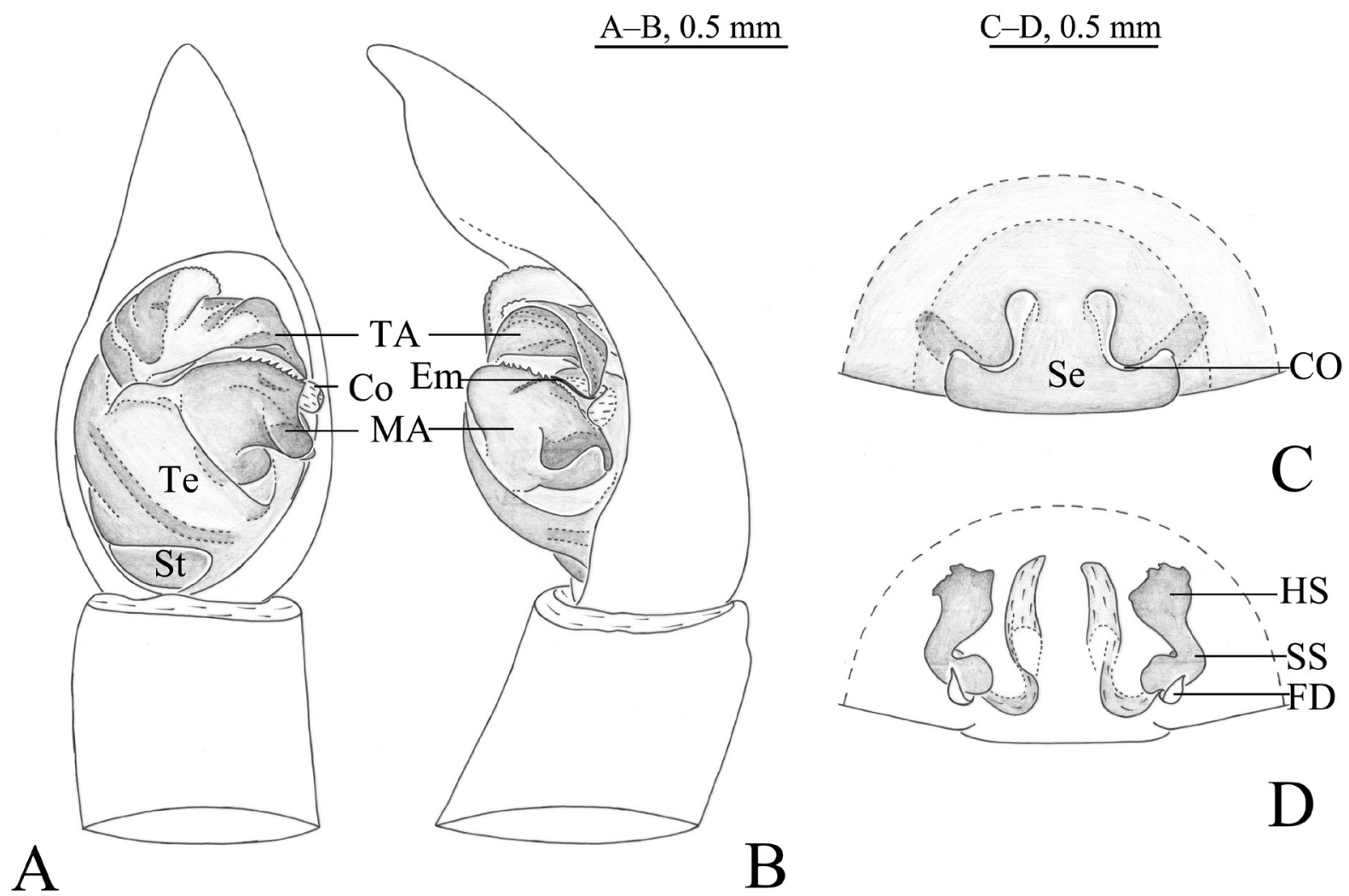

Fig. 2. Serratacosa medogensis gen. et sp. nov. A-B. Holotype, $\widehat{\jmath}$ (SWUC-T-LY-12-01). C-D. Paratype, (SWUC-T-LY-12-08). A. Left pedipalp, ventral view. B. Left pedipalp, retrolateral view. C. Epigyne, ventral view. D. Vulva, dorsal view. 
95¹1.022' E; alt. 924 m; 23 May 2019; L.Y. Wang, P. Liu, T. Yuan and H. Wang leg; SWUC-T-LY-12-23 to $12-27 \bullet 4 \partial^{\lambda}, 1$; ; Medog County; $29^{\circ} 19.470^{\prime}$ N, $95^{\circ} 19.618^{\prime}$ E; alt. 1116 m; 23 May 2019; L.Y. Wang, P. Liu, T. Yuan and H. Wang leg.; SWUC-T-LY-12-28 to 12-32 1 o ; Medog County, Medog Town, Yarang Village; $29^{\circ} 17.758^{\prime} \mathrm{N}, 95^{\circ} 16.827^{\prime} \mathrm{E}$; alt. $761 \mathrm{~m}$; 28 Jun. 2018; L.Y. Wang, Z.S. Wu and Y.N. Mu leg.; SWUC-T-LY-12-33 • 4 우; Medog County, Beibeng Township; $29^{\circ} 14.376^{\prime}$ N, $95^{\circ} 10.675^{\prime}$ E; alt. 894 m; 28 Jun. 2018 L.Y. Wang, Z.S. Wu and Y.N. Mu leg.; SWUC-T-LY-12-34 to 12-37 1 O; Medog County; $29^{\circ} 19.470^{\prime}$ N, 95¹9.618' E; alt. 1116 m; 28 Jun. 2018; L.Y. Wang, Z.S. Wu and Y.N. Mu leg; SWUC-T-LY-12-38.

\section{Description}

Male (holotype, Fig. 3A)
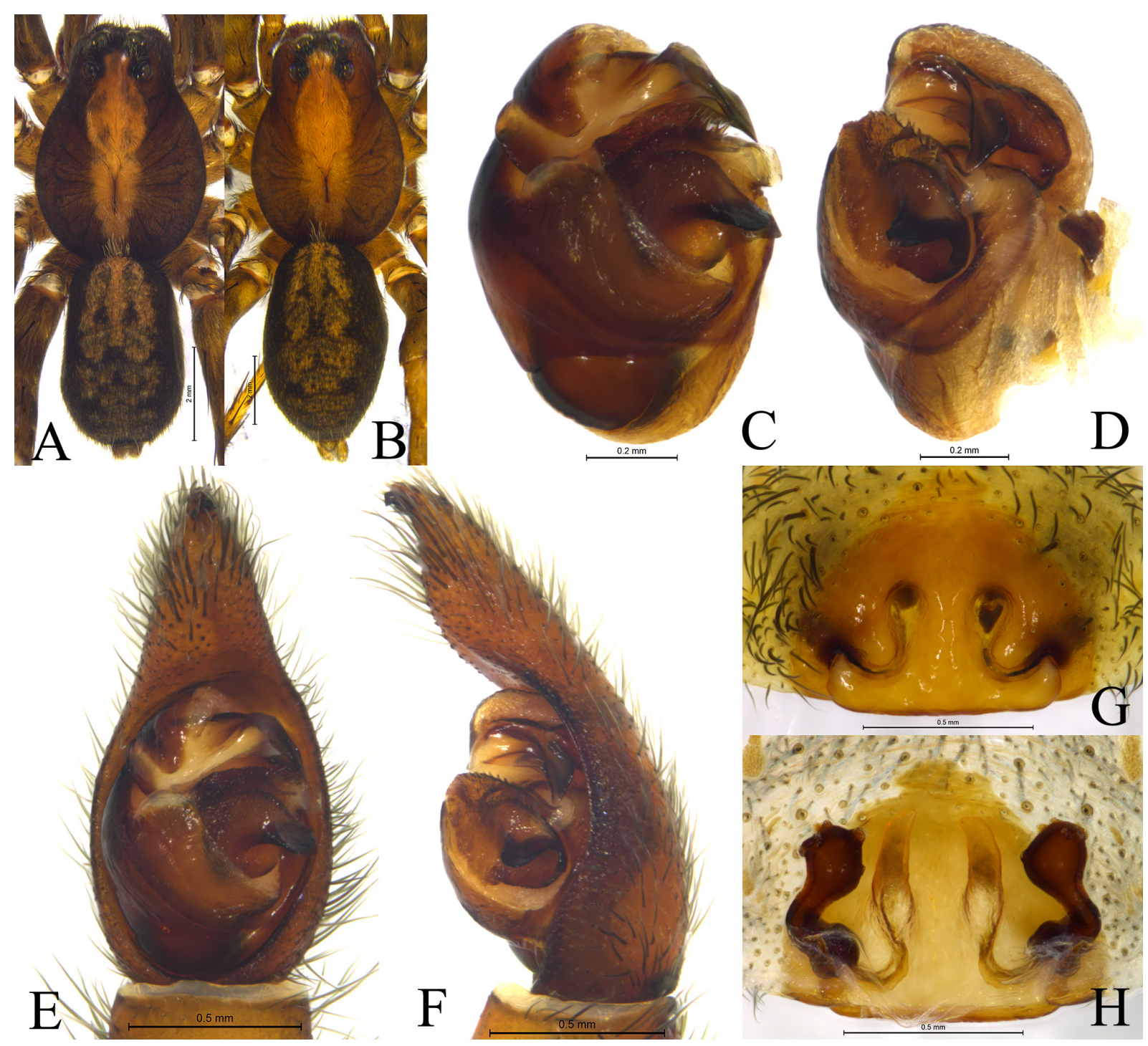

Fig. 3. Serratacosa medogensis gen. et sp. nov. A, E-F. Holotype, $\widehat{o}$ (SWUC-T-LY-12-01). B.

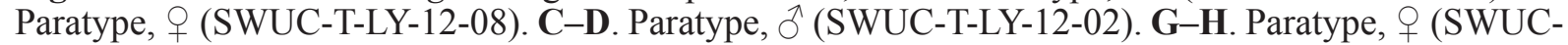
T-LY-12-08). A. Male habitus, dorsal view. B. Female habitus, dorsal view. C. Left pedipalp, bulbus, ventral view. D. Left pedipalp, bulbus, retrolateral view. E. Left pedipalp, ventral view. F. Left pedipalp, retrolateral view. G. Epigyne, ventral view. H. Vulva, dorsal view. 
Measurements. Total length 9.03. Carapace 5.13 long, 3.69 wide; opisthosoma 4.09 long, 2.68 wide. Eye sizes and interdistances: $\mathrm{AME}=0.21, \mathrm{ALE}=0.17, \mathrm{PME}=0.49, \mathrm{PLE}=0.39$; $\mathrm{AME}-\mathrm{AME}=0.11$, $\mathrm{AME}-\mathrm{ALE}=0.09, \mathrm{PME}-\mathrm{PME}=0.32, \mathrm{PME}-\mathrm{PLE}=0.35$. Clypeus height 0.16 .

LEG MEASUREMENTS. I $=13.35(3.81,4.33,3.01,2.20)$; II $=12.75(3.55,4.33,2.95,1.92) ; \mathrm{III}=11.82$ $(3.33,3.65,3.11,1.73) ; \mathrm{IV}=16.98(4.50,4.84,5.26,2.38)$.

Male Pedipalp (Figs 1, 2A-B, 3C-F). Subtegulum distinct in ventral view, located baso-prolaterally. Embolus slender and slightly sinuous. Conductor small and membranous. Median apophysis serrated, ventral surface with semicircular protruding lobe, strongly sclerotized, dorsal surface with oval sclerite. Terminal apophysis strong twisted, distal end grooved.

Female (SWUC-T-LY-12-02, Fig. 3B)

Measurements. Total length 12.36. Carapace 6.65 long, 4.49 wide; opisthosoma 6.06 long, 3.69 wide. Eye sizes and interdistances: $\mathrm{AME}=0.28, \mathrm{ALE}=0.21, \mathrm{PME}=0.58, \mathrm{PLE}=0.48$; $\mathrm{AME}-\mathrm{AME}=0.19$, $\mathrm{AME}-\mathrm{ALE}=0.10, \mathrm{PME}-\mathrm{PME}=0.43, \mathrm{PME}-\mathrm{PLE}=0.44$. Clypeus height 0.28.

Leg MEASUREMENTS. I $=14.82(4.34,4.88,3.20,2.40) ; \mathrm{II}=14.17(4.06,4.79,3.14,2.18) ; \mathrm{III}=13.57$ $(3.84,4.22,3.43,2.08) ; \mathrm{IV}=19.17(4.98,6.01,5.59,2.59)$.

Epigyne (Figs 2C-D, 3G-H). Epigyne with inverted T-shaped septum, median part wider than long. Copulatory openings located on shoulders of septum. Spermathecal heads large and spherical, with several small buds. Spermathecal stalks short, curved. Fertilization ducts hook-like.

\section{Distribution}

China (Tibet, Medog County) (Fig. 6).

Serratacosa multidontata (Qu, Peng \& Yin, 2010) comb. nov. http://zoobank.org/f5b258d3-c866-4d01-9324-1fb7bec017e4

Figs 4-6

Pardosa multidontata Qu, Peng \& Yin, 2010: 392, figs 5a-b, 11a-e (ぷ+ ).

\section{Diagnosis}

This species resembles $S$. medogensis gen. et sp. nov. (Figs 1-3), but differs by having the distal end of the lateral projection of the median apophysis truncate, almost overlapping the lateral edge of the cymbium in this species (Figs 4A-B, 5C-F), whereas this end is blunt, slightly touching the lateral edge of the cymbium in ventral view in S. medogensis gen. et sp. nov. (Figs 1C-D, 2A-B, 3C-F). The septum longer than wide and the spermathecal heads are oval with thick spermathecal stalks in this species (Figs 4C-D, 5G-H), whereas the septum is wider than long and the spermathecal heads are spherical with fine spermathecal stalks in S. medogensis gen. et sp. nov. (Figs 2C-D, 3G-H)

\section{Material examined}

Holotype

China ${ }^{\lambda}$; Yunnan Province, Gongshan County, Dulongjiang Township, Qing Lang Dang; $27^{\circ} 41.418^{\prime}$ N, 98¹6.740' E; alt. 1309 m; 31 Aug. 2006; P. Hu leg.; HNU.

\section{Paratypes}

China $・ 1$ गे, 4 9 \% ; same collection data as for holotype; HNU. 


\section{Description}

Male (holotype, Fig. 5A)

Measurements. Total length 10.04. Carapace 5.25 long, 4.01 wide; opisthosoma 4.83 long, 3.16 wide. Eye sizes and interdistances: $\mathrm{AME}=0.26, \mathrm{ALE}=0.18, \mathrm{PME}=0.56, \mathrm{PLE}=0.46$; $\mathrm{AME}-\mathrm{AME}=0.13$, $\mathrm{AME}-\mathrm{ALE}=0.11, \mathrm{PME}-\mathrm{PME}=0.34, \mathrm{PME}-\mathrm{PLE}=0.44$. Clypeus height 0.14 .

Leg MEASUREMENTS. $\mathrm{I}=13.64(3.63,4.83,3.02,2.16) ; \mathrm{II}=12.71(3.57,4.10,2.93,2.11) ; \mathrm{III}=12.06$ $(3.25,3.86,3.16,1.79) ; \mathrm{IV}=16.89(4.34,5.15,5.12,2.28)$.

Male pedipalp (Figs 4A-B, 5C-F). Subtegulum distinct in ventral view, located baso-prolaterally. Embolus slender and slightly sinuous. Conductor small and membranous. Median apophysis serrated, ventral surface with semicircular protruding lobe, strongly sclerotized, dorsal surface with oval sclerite. Terminal apophysis strong, twisted, distal end grooved.

\section{Female (Fig. 5B)}

MeAsurements. Total length 13.14. Carapace 6.60 long, 4.95 wide; opisthosoma 6.92 long, 5.11 wide. Eye sizes and interdistances: $\mathrm{AME}=0.33, \mathrm{ALE}=0.23, \mathrm{PME}=0.64, \mathrm{PLE}=0.57$; $\mathrm{AME}-\mathrm{AME}=0.18$, $\mathrm{AME}-\mathrm{ALE}=0.15, \mathrm{PME}-\mathrm{PME}=0.44, \mathrm{PME}-\mathrm{PLE}=0.53$. Clypeus height 0.31 .

LEG MEASUREMENTS. I $=15.53(4.54,5.56,3.08,2.35) ; \mathrm{II}=13.61(4.21,4.16,3.14,2.10) ; \mathrm{III}=13.53$ $(3.80,4.44,3.28,2.01) ; \mathrm{IV}=20.23(5.12,6.49,5.58,3.04)$.
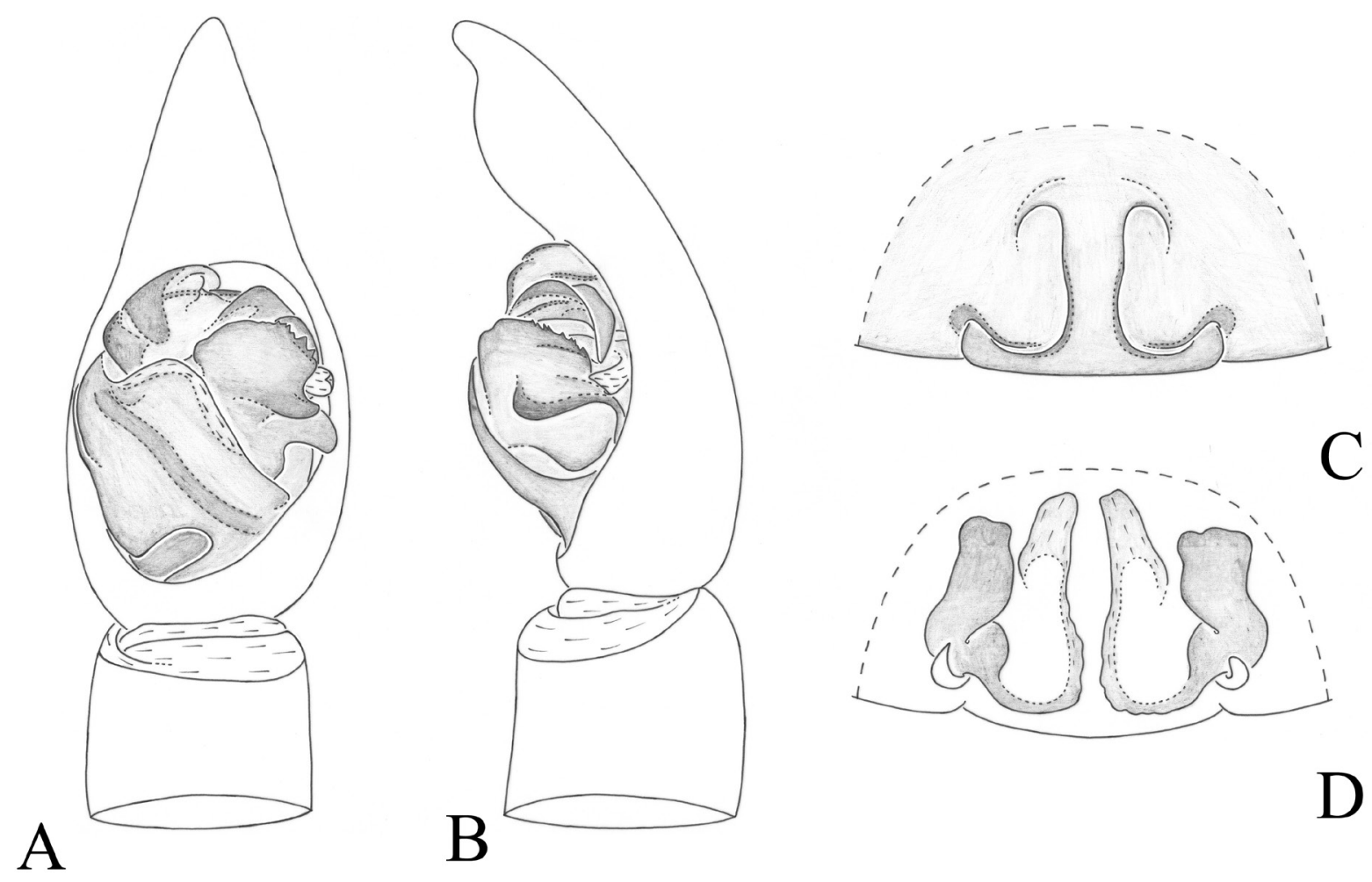

Fig. 4. Serratacosa multidontata (Qu, Peng \& Yin, 2010) comb. nov. A-B. Paratype, §̂ (HNU). C-D. Paratype, $q$ (HNU). A. Left pedipalp, ventral view. B. Left pedipalp, retrolateral view. C. Epigyne, ventral view. D. Vulva, dorsal view. 
Epigyne (Figs 4C-D, 5G-H). Epigyne with inverted T-shaped septum, median part wider than long. Copulatory openings located on shoulders of septum. Spermathecal heads oval. Spermathecal stalks thick, short and curved. Fertilization ducts hook-like.

\section{Distribution}

China (Yunnan) (Fig. 6).

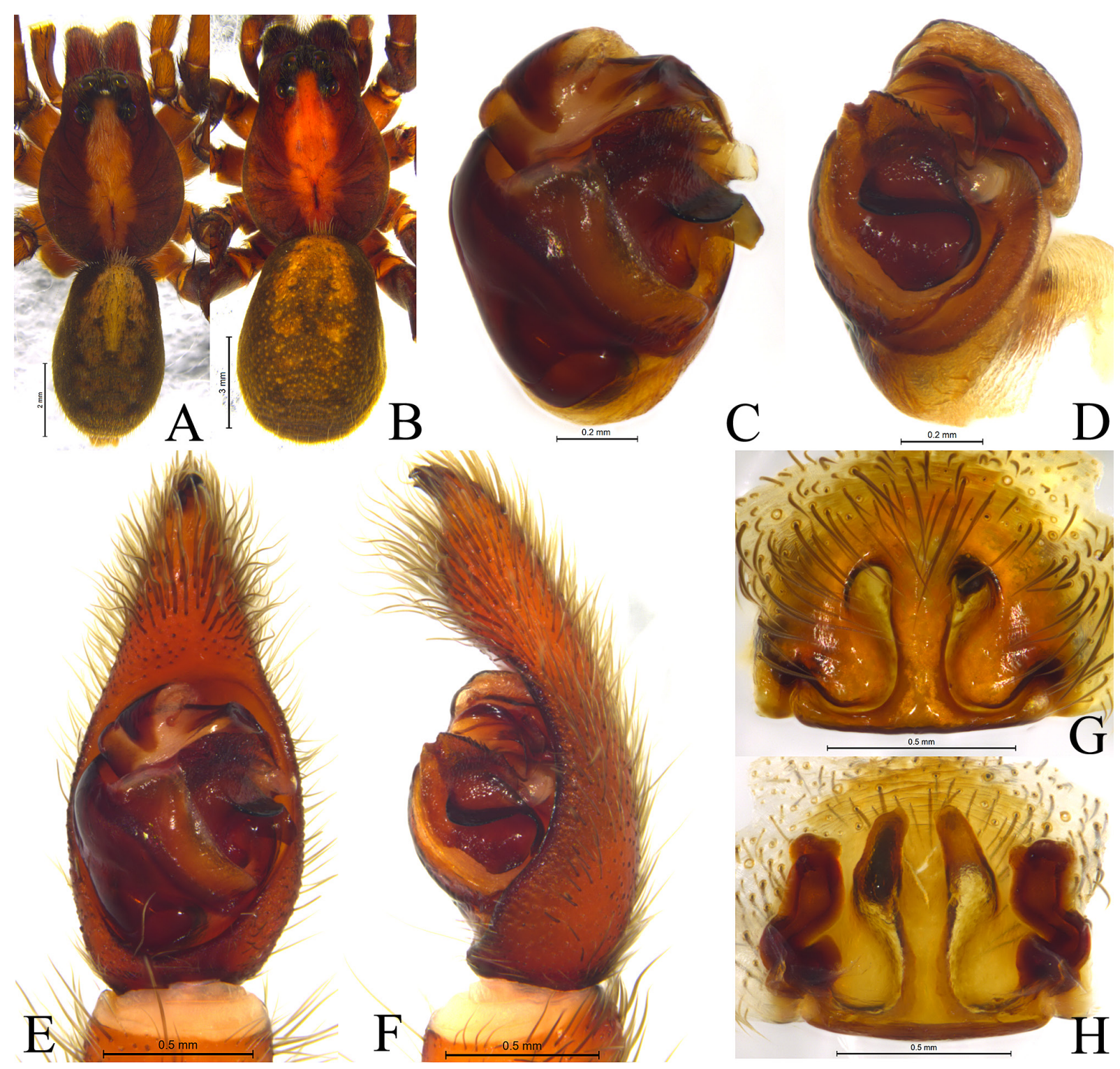

Fig. 5. Serratacosa multidontata (Qu, Peng \& Yin, 2010) comb. nov. A. Holotype, $\widehat{\partial}$ (HNU). B. Paratype, $\uparrow$ (HNU). C-F. Paratype, $\overbrace{}^{\lambda}(\mathrm{HNU})$. G-H. Paratype, $q$ (HNU). A. Male habitus, dorsal view. B. Female habitus, dorsal view. C. Left pedipalp, bulbus, ventral view. D. Left pedipalp, retrolateral view. E. Left pedipalp, ventral view. F. Left pedipalp, retrolateral view. G. Epigyne, ventral view. H. Vulva, dorsal view. 


\section{Discussion}

Based on the following characteristics, Serratacosa gen. nov. can be identified as a member of the subfamily Lycosinae: median apophysis transverse, with ventrally directed spur and dorsal surface with a sinuous channel; epigyne with an inverted 'T-shaped' median septum (Dondale 1986; Piacentini \& Grismado 2009).

Wolf spiders mainly live in open habitats (Jocqué \& Alderweireldt 2005). Serratacosa gen. nov. is distributed from the southern slopes of the Eastern Himalayas to the very dense forests on the southern slopes. Both S. medogensis gen. et sp. nov. and S. multidontata (Qu, Peng \& Yin, 2010) comb. nov. were found in dense forests. All three species addressed in this study have been recorded from the southern slopes of the Eastern Himalayas, which might indicate that the species differentiation of the members of the genus Serratacosa gen. nov. is closely related to the uplift of the Qinghai-Tibet Plateau. It can be proposed that there are still many undescribed species on the southern slopes of the Eastern Himalayas awaiting discovery and description.

\section{Acknowledgments}

Many thanks are given to our research team members in SWUC (Mr. Zhi-Sun Wu, Tao Yuan and Ms. Piao Liu) and the College of Life Sciences, Hebei University, Baoding, China (Mr. Yan-Nan Mu and Ms. Hui Wang) for their assistance during the field work and collection. We are also thankful to Dr Stephanie F. Loria (American Museum of Natural History, New York) for reviewing the English of this manuscript. This work was supported by the Fundamental Research Funds for the Central Universities

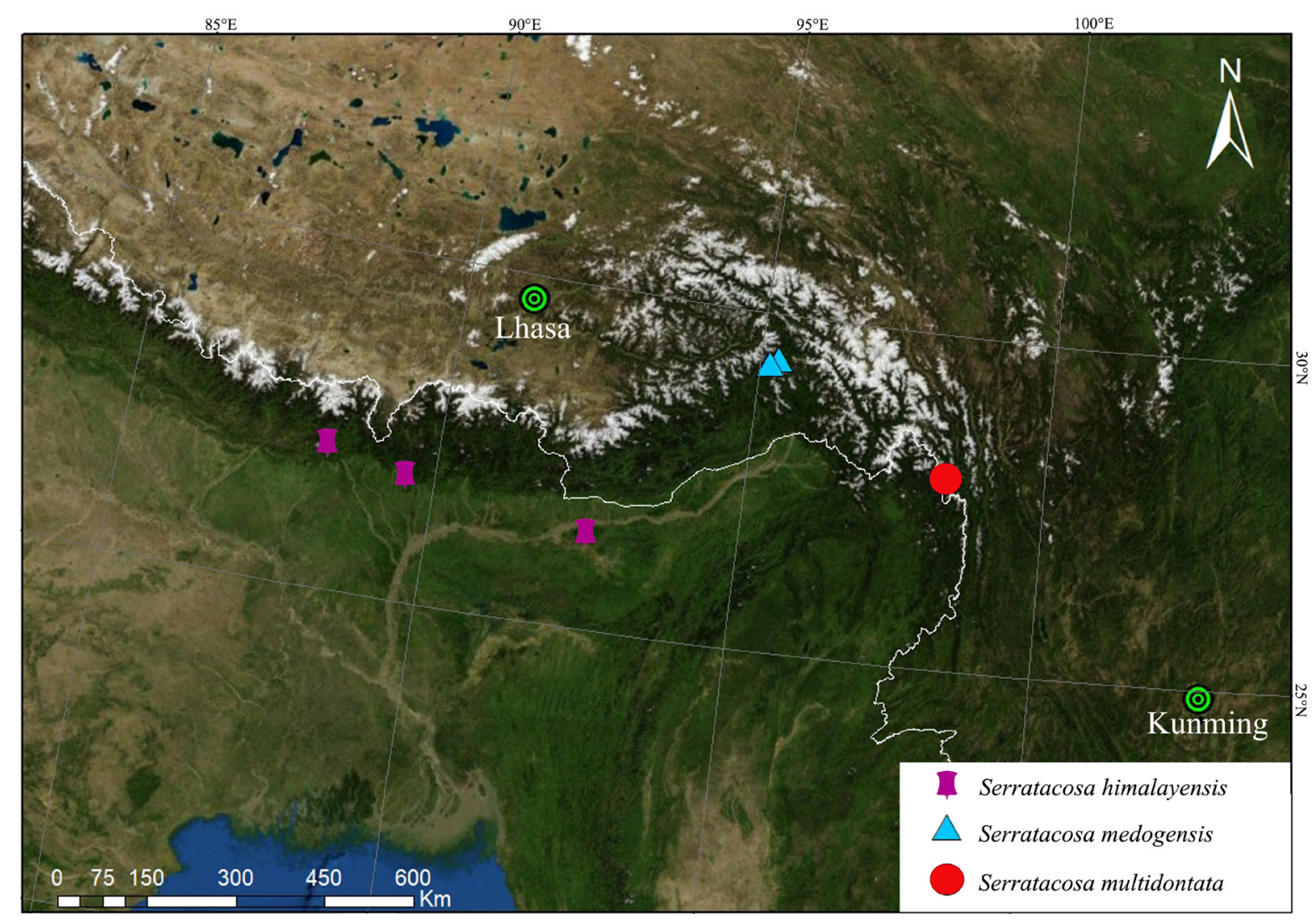

Fig. 6. Distribution of Serratacosa gen. nov. 
(SWU120051), the National Natural Science Foundation of China (31672278, 31702005), the Key Natural Science Foundation of Chongqing (cstc2019jcyj-zdxmX0006) and the Investigation Project of Basic Science and Technology (2018FY100305) to Zhi-Sheng Zhang and Lu-Yu Wang.

\section{References}

Almquist S. 2005. Swedish Araneae, part 1 - families Atypidae to Hahniidae (Linyphiidae excluded). Insect Systematics \& Evolution, Supplement 62: 1-284.

Buchar J. 1997. Lycosidae aus Bhutan 1. Venoniinae und Lycosinae (Arachnida: Araneae). Entomologica Basiliensis 20: 5-32.

Dondale C.D., 1986. The subfamilies of wolf spiders (Araneae: Lycosidae). Actas X Congreso Internacional de Aracnología 1: 327-332.

Framenau, V.W.2007. Revision of the new Australian genus Artoriopsis in a new subfamily of wolf spiders, Artoriinae (Araneae: Lycosidae). Zootaxa 1391 (1): 1-34. https://doi.org/10.11646/zootaxa.1391.1.1

Framenau V.W. \& Leung, A.E. 2013. Costacosa, a new genus of wolf spider (Araneae, Lycosidae) from coastal north-west Western Australia. Records of the Western Australian Museum, Supplement 83: 173-184. https://doi.org/10.18195/issn.0313-122x.83.2013.173-184

Gravely F.H. 1924. Some Indian spiders of the family Lycosidae. Records of the Indian Museum, Calcutta 26: 587-613.

Jocqué R., Alderweireldt M., 2005. Lycosidae: the grassland spiders. Acta Zoologica Bulgarica, Supplement 1: 125-130.

Logunov D.V. 2020. On three species of Hogna Simon, 1885 (Aranei: Lycosidae) from the Near East and Central Asia. Arthropoda Selecta 29 (3): 349-360. https://doi.org/10.15298/arthsel.29.3.08

Lu T., Koh J.K.H., Zhang Z.S. \& Li S.Q. 2018. A new Ovia species (Araneae, Lycosidae) from Singapore, with the transfer of Pardosa alboannulata Yin et al., 1997. Zootaxa 4527 (3): 436-450. https://doi.org/10.11646/zootaxa.4527.3.12

Marusik Y.M., Azarkina G.N. \& Koponen S. 2004. A survey of east Palearctic Lycosidae (Aranei). II. Genus Acantholycosa F. Dahl, 1908 and related new genera. Arthropoda Selecta 12 (2): 101-148.

Myers N., Mittermeier R.A., Mittermeier C.G., da Fonseca G.A.B. \& Kent J. 2000. Biodiversity hotspots for conservation priorities. Nature 403: 853-858. https://doi.org/10.1038/35002501

Piacentini L.N. \& Grismado C.J. 2009. Lobizon and Navira, two new genera of wolf spiders from Argentina (Araneae: Lycosidae). Zootaxa 2195 (1): 1-33. https://doi.org/10.11646/zootaxa.2195.1.1

Piacentini L.N. \& Ramírez M.J. 2019. Hunting the wolf: a molecular phylogeny of the wolf spiders (Araneae, Lycosidae). Molecular Phylogenetics and Evolution 136: 227-240.

https://doi.org/10.1016/j.ympev.2019.04.004

Qu L.L., Peng X.J. \& Yin C.M. 2010. Six new species of the spider genus Pardosa (Araneae: Lycosidae) from Yunnan, China. Oriental Insects 44: 387-404. https://doi.org/10.1080/00305316.2010.10417623

Sankaran P.M., Malamel J.J. \& Sebastian P.A. 2017. On the new monotypic wolf spider genus Ovia gen. nov. (Araneae: Lycosidae, Lycosinae). Zootaxa 4221 (3): 366-376.

https://doi.org/10.11646/zootaxa.4221.3.5

Tikader B.K. \& Malhotra M.S. 1980. Lycosidae (wolf-spiders). Fauna India (Araneae) 1: 248-447. 
Wang L.Y., Li Z.X., Zhou K.X. \& Zhang Z.S. 2015. Redescription of three Hippasa species from China (Araneae: Lycosidae), with a proposed species group-division and diagnosis. Zootaxa 3974 (2): 231244. https://doi.org/10.11646/zootaxa.3974.2.7

World Spider Catalog 2021. World Spider Catalog. Version 22.0. Natural History Museum Bern. Available from http://wsc.nmbe.ch [accessed 11 May 2021].

Manuscript received: 21 December 2020

Manuscript accepted: 24 May 2021

Published on: 10 August 2021

Topic editor: Rudy Jocqué

Desk editor: Eva-Maria Levermann

Printed versions of all papers are also deposited in the libraries of the institutes that are members of the EJT consortium: Muséum national d'histoire naturelle, Paris, France; Meise Botanic Garden, Belgium; Royal Museum for Central Africa, Tervuren, Belgium; Royal Belgian Institute of Natural Sciences, Brussels, Belgium; Natural History Museum of Denmark, Copenhagen, Denmark; Naturalis Biodiversity Center, Leiden, the Netherlands; Museo Nacional de Ciencias Naturales-CSIC, Madrid, Spain; Real Jardín Botánico de Madrid CSIC, Spain; Zoological Research Museum Alexander Koenig, Bonn, Germany; National Museum, Prague, Czech Republic. 